\title{
A DEDUÇÃO DAS CATEGORIAS NA PRIMEIRA EDIÇÃO DA CRÍTICA DA RAZÃO PURA DE KANT
}

\author{
Udo Baldur Moosburger \\ Universidade Federal do Paraná
}

in memoriam Valério Rohden

Resumo: A presente publicação é uma homenagem póstuma a Valério Rohden, o principal incentivador dos estudos kantianos no Brasil ao longo das últimas quatro décadas. Contém uma tradução da Dedução das categorias da primeira edição da Crítica da razão pura de Kant. A tradução é complementada com algumas notas referentes a possivveis interpretações divergentes de partes do texto, indicando eventuais ambiguidades da formulação original de Kant e sugerindo versões alternativas quando for o caso.

Palavras-chave: Kant, Crítica da razão pura, Dedução das categorias na edição $\mathrm{A}$

Abstract: The present publication is a tribute to the late Valério Rohden, the chief mentor of Kantian studies in Brazil over the last four decades. It contains a translation of the Deduction of the Categories as it is found in the first edition of Kant's Critique of Pure Reason. The translation is complemented with some notes bearing on possible diverging interpretations of a part of the text, indicating eventual ambiguities of Kant's original formulation and suggesting alternative renditions where appropriate.

Keywords: Kant, Critique of Pure Reason, Deduction of the Categories in edition A

Há mais de trinta anos foi publicada no Brasil a primeira tradução completa da Crítica da razão pura de Kant para o português. A primeira edição desta tradução comportou apenas uma parte do texto de Kant. Poucos sabem que a publicação da íntegra desta tradução deveu-se ao engajado esforço de Valério Rohden junto ao editor. Mesmo assim, apenas a versão da segunda edição publicada em vida de Kant foi apresentada ao público leitor brasileiro. Nesta oportunidade, não foi possível a Valério Rohden mover o editor a incluir naquela publicação as variantes da primeira edição da obra de Kant. 
Quando Valério Rohden procurou-me há alguns anos para que refizéssemos a tradução da Crítica da razão pura, seu plano era o de apresentar o texto agora munido também de todas as passagens que só constam da primeira edição daquela obra. Fiquei encarregado de traduzir estas passagens - trata-se do prefácio da primeira edição da Crítica da razão pura, da primeira versão da dedução das categorias e de um longo trecho sobre os paralogismos da razão pura - para que elas fossem incluídas em uma publicação futura, agora sim completa, do texto de Kant. Infelizmente duas panes, uma no computador de Valério Rohden e outra no meu computador, fizeram desaparecer no elemento virtual as traduções destas variantes. As tentativas especializadas de recuperação deste material só surtiram efeito para o texto relativo à dedução das categorias, e as traduções dos dois outros textos devem ser agora dadas como irremediavelmente perdidas.

O último grande plano acalantado por Valério Rohden foi o de publicar integralmente em português todas as obras que Kant publicara em vida. Em conversas privadas mencionou-o seguidamente, embora ainda não tivesse procurado um editor que ousasse assumir a realização deste plano. Chegamos a iniciar em conjunto uma revisão da tradução da Crítica da razão pura feita há várias décadas. A intenção manifesta de Valério Rohden era a de incluir, no texto da tradução desta obra de Kant previsto para este projeto, todas as variantes que distinguem a sua primeira da sua segunda edição. Em meio a esta atividade ocorreu o passamento de Valério Rohden. Nada mais justo, portanto, que a presente publicação seja dedicada ao seu mentor como um modesto tributo de agradecimento e de reconhecimento póstumos.

O texto que se lerá a seguir não se beneficiou da crítica daquele que, por sua vasta erudição in rebus kantianis, estava habilitado como ninguém para exercê-la. Quem sabe a sua publicação tal como está possa ainda render algum serviço a quem, no futuro, se dispuser a reencetar um projeto como o nutrido por Valério Rohden pouco antes de morrer. De modo geral, a tradução foi concebida para ser lida tanto por um leitor nativo monoglota do português quanto por alguém que possa e queira confrontar com o original o texto aqui apresentado. Isto requer a explicação de algumas convenções tipográficas adotadas no texto.

Como regra geral, todos os grifos no texto são de Kant. Além disso, tudo o que estiver entre parênteses () é texto de Kant e tudo o que estiver entre colchetes [] é acréscimo do tradutor. Estes acréscimos são de tipo variado. Em primeiro lugar, inseriu-se, sempre no início da página à qual se refere, a paginação original da primeira edição da Crítica da razão pura, paginação que aparece, por exemplo, na forma [A 102]. Em segundo lugar, também entre colchetes foram inseridas as indicações de notas do tradutor. 
Estas notas do tradutor, reconhecíveis por sua numeração contínua, podem ser distinguidas das notas de Kant, que são apenas duas e aparecem indicadas no texto por $*$ e por $* *$. Em terceiro lugar, aqui e ali introduziram-se complementos ao texto de Kant. A leitura do texto com estes complementos facilitará, espera-se, a compreensão do texto por parte de um leitor que dependa da versão portuguesa para aceder ao pensamento de Kant. Os que têm acesso ao texto original poderão por seu turno julgar estas inserções, principalmente onde esclarecem e/ou interpretam os termos anafóricos de que abunda o texto de Kant. Neste terceiro tipo de inserção muita coisa é matéria controversa, e a multiplicidade de referências possíveis dos termos anafóricos certamente foi ocasião para que se instalassem erros, este horror dos críticos. Aqui não há outro remédio senão contar com a crítica de um leitor benevolente. Em todo caso, à objeção que as inserções deste tipo tenham sido muito numerosas e até extensas poder-se-á responder que o intuito foi o de distinguir, em cada caso, o texto kantiano de sua interpretação.

A base da presente tradução foi o texto da Crítica da razão pura editado por Weischedel. Esta edição da Crítica da razão pura era a predileta de Valério Rohden. As variantes da edição da Academia para esta passagem da obra são de somenos importância, não tendo influência alguma sobre as opções de tradução. As variantes apresentadas por edições mais antigas, ou que são fruto do labor destes eruditos de antanho, estão convenientemente consignadas em notas de rodapé na edição de Raymund Schmidt. Na tradução a seguir foram mencionadas apenas aquelas variantes que têm algum alcance para determinar a tradução ou a interpretação prima facie da passagem correspondente. Nas notas, portanto, neste caso foi preciso apenas remeter o leitor à edição de Schmidt.

\section{Siglas usadas nas notas}

Emmel/Red H. Emmel/Red. Gemüt I. Historisches Wörterbuch der Philosophie, hrsg. von Joachim Ritter. Band 3: G-H. Darmstadt: Wissenschaftliche Buchgesellschaft, 1974, col. 258-262.

KrV SchmidtImmanuel Kant. Kritik der reinen Vernunft. Nach der ersten und zweiten Original-Ausgabe neu herausgegeben von Raymund Schmidt. Zweite, durchgesehene, um ein Namenregister vermehrte Auflage. Hamburg: Felix Meiner Verlag, 1930. 


\begin{abstract}
WW Immanuel Kant. Werke in zehn Bänden. Hrsg. von Wilhelm Weischedel. Sonderausgabe. Darmstadt: Wissenschaftliche Buchgesellschaft, 1981.
\end{abstract}

\title{
Texto
}

[A 94] Mas são três as fontes originárias (capacidades ou faculdades da alma) que contêm as condições de possibilidade de toda experiência e que não podem elas mesmas ser derivadas de nenhuma outra faculdade da mente[ $\left.{ }^{1}\right]$, a saber sentido, imaginação e apercepção. Nisto funda-se 1) a sinopse do múltiplo a priori pelo sentido, 2) a síntese deste múltiplo pela imaginação, finalmente 3) a unidade desta síntese por apercepção originária. Todas estas faculdades têm, afora o uso empírico, ainda um uso transcendental, que incide unicamente na forma e é possível a priori. Deste [uso] falamos com respeito aos sentidos acima na primeira parte, [A 95] mas as duas outras queremos buscar compreender agora segundo a sua natureza.

\footnotetext{
1 No original: "Gemüt". Este termo é notoriamente difícil de ser traduzido. Vertê-lo por "ânimo", tradução propugnada por Valério Rohden em várias discussões orais, é certamente provocar estranheza no leitor. Nas fases iniciais de desenvolvimento da língua alemã o termo "Gemüt" parece não ter tido seu significado fixado de modo unívoco. O seu emprego moveu-se no campo semântico do termo grego

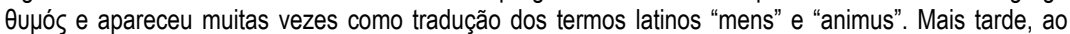
longo do século XVIII, passou a ser tendencialmente usado para designar uma sede unificadora dos desejos, da vontade e dos afetos ou o seu conjunto (cf. Emmel/Red. col. 258 e seg. com várias referências). Na segunda edição da Crítica da razão pura Kant empregou o termo "Gemüt" como designação ampla de uma unidade da qual se originariam duas fontes fundamentais de conhecimento, a receptividade das impressões e a espontaneidade dos conceitos (cf. KrV B 74), e nesta obra Kant parece não ter definido de modo mais circunscrito este termo. Definido desta maneira geral, o termo poderia ser perfeitamente traduzido por "mente". Esta tradução, embora podendo abonar-se do uso do termo em fases anteriores da língua alemã, também não deixa de ser problemática em um contexto kantiano. No escrito Verkündigung des nahen Abschlusses eines Traktats zum ewigen Frieden in der Philosophie, datado de 1796, Kant usou o termo "Geist" como sinônimo de "mens" e de vous para designar o que a razão acrescenta à alma a fim de permitir-lhe uma vida adequada à espontaneidade da liberdade (cf. WW 5 p. 410). É sabido que a língua alemã não dispõe de um substantivo que corresponda exatamente ao latim "mens", o que teve algumas consequências nem sempre virtuosas para 0 desenvolvimento da filosofia alemã pós-kantiana, bastando lembrar aqui o uso muitas vezes equívoco que Hegel fez do termo "Geist". O problema da tradução de "Gemüt" em Kant talvez não tenha uma solução satisfatória. Se aqui foi traduzido por "mente" pace Valério Rohden, deveu-se-o à convicção do tradutor de que, na maioria das passagens em que o original ostenta "Gemüt", inserir no texto português "mente" faz sentido inteligível tanto a qualquer falante nativo de português quanto a um filósofo profissional que estiver analisando tecnicamente o texto de Kant.
} 


\title{
Dedução dos Conceitos Puros do Entendimento
}

\author{
Segunda Seção
}

Das razões a priori para a possibilidade da experiência

Que um conceito deva ser produzido de modo completamente a priori e se referir a um objeto, embora ele mesmo não faça parte do conceito de experiência possível nem consista de elementos de uma experiência possível, é inteiramente contraditório e impossível. Pois então ele não teria conteúdo algum pelo fato de não lhe corresponder intuição alguma, na medida em que intuições em geral, pelas quais objetos podem nos ser dados, constituem o campo ou o objeto todo de experiência possível. Um conceito a priori que não se referisse a esta [experiência] seria apenas a forma lógica para um conceito, mas não o próprio conceito pelo qual algo fosse pensado.

Se há portanto conceitos puros a priori, eles certamente não podem conter nada de empírico, mas têm não obstante que ser puras condições a priori para uma experiência possível como [aquelas] unicamente sobre as quais pode repousar a sua realidade objetiva.

Caso se queira portanto saber como são possíveis conceitos puros do entendimento, é preciso investigar quais são as condições [A 96] a priori que importam à possibilidade da experiência e que lhe subjazem $\left[{ }^{2}\right]$, mesmo que se abstraia de tudo o que é empírico nos fenômenos. Um conceito que expressasse de modo universal e suficiente esta condição formal e objetiva da experiência denominar-se-ía um conceito puro do entendimento. Uma vez que eu tenha conceitos puros do entendimento, também posso muito bem excogitar $\left[{ }^{3}\right]$ objetos que podem talvez ser impossíveis, talvez até em si possíveis, mas que não podem ser dados em experiência alguma na medida em que, na conexão daqueles conceitos, pode ter sido deixado de lado algo que apesar disso pertence necessariamente à condição de uma experiência possível (conceito de um espírito[ $\left.{ }^{4}\right]$ ) ou que talvez conceitos puros do entendimento sejam estendidos além daquilo que a experiência pode

\footnotetext{
2 No original: "die ihr zum Grunde liegen". Por respeitar o uso vernáculo e corresponder ao significado da expressão alemã no uso normal da língua, doravante o verbo "subjazer" será sempre empregado para traduzir esta expressão alemã. Convém contudo observar que, na tradução, o verbo "subjazer" deve ser interpretado em sentido forte. Traduções alternativas ipsis verbis, mas um tanto deselegantes seriam "que lhe estão na base" ou "que lhe são fundamento".

${ }^{3}$ No original: "erdenken", no sentido de "inventar em pensamento" ou de "obter pelo pensamento".

${ }^{4}$ No original: "eines Geistes". Uma tradução alternativa seria "de uma mente". Cf. mais acima nota 1.
} 
abranger (conceito de Deus). Mas os elementos para todos os conhecimentos a priori, mesmo para ficções arbitrárias e disparatadas, não podem, é claro, ser tomados de empréstimo da experiência (pois senão não seriam conhecimentos a priori), mas precisam sempre conter as condições puras a priori de uma experiência possível e de um objeto da mesma, pois de outro modo não só nada poderia ser pensado por eles, mas também eles mesmos, sem dados, não poderiam surgir nem mesmo no pensamento.

Ora, estes conceitos, os quais contêm a priori o pensamento puro que está $\left.{ }^{5}\right]$ em toda experiência, nós os encontramos nas categorias, e já é uma dedução suficiente das mesmas e uma justificativa de sua validade objetiva [A 97] se pudermos provar que um objeto pode ser pensado unicamente por seu intermédio. Mas por num tal pensamento estar ocupado mais do que a única faculdade de pensar, a saber o entendimento, e por ele mesmo, como uma faculdade de conhecimento que deve se referir a objetos, precisar igualmente de uma elucidação quanto à possibilidade desta referência, temos antes que ponderar, não quanto à sua conformação $\left[{ }^{6}\right]$ empírica, mas sim quanto à transcendental, as fontes subjetivas que perfazem a base a priori para a possibilidade da experiência.

Se cada representação singular fosse inteiramente estranha a outra, por assim dizer isolada e separada dela, então jamais surgiria algo como é o conhecimento, o qual é um todo de representações comparadas e conectadas. Se eu portanto juntar $\left[^{7}\right]$ uma sinopse ao sentido por este conter multiplicidade em sua intuição, então a esta [sinopse] corresponde sempre uma síntese e a receptividade pode tornar possíveis conhecimentos somente ligada à espontaneidade. Ora, esta [última] é o fundamento de uma tripla síntese que ocorre de modo necessário em todo conhecimento, a saber a da apreensão das representações como modificações da mente na intuição, a da reprodução das mesmas na imaginação e a do seu reconhecimento [Rekognition] no conceito. Estas [sínteses] dão uma indicação de três fontes subjetivas de conhecimento que tornam possíveis o próprio entendimento e, através dele, toda [A 98] experiência como um produto empírico do entendimento.

\footnotetext{
${ }^{5}$ No original: "bei". É difícil traduzir exatamente esta preposição de sentido locativo, que corresponde ao francês "chez". Poder-se-ía também traduzir por "insito em", por "que acompanha" ou algo similar. Ao longo do texto esta preposição será traduzida diversamente conforme o contexto em que ocorra.

${ }^{6}$ No original: "Beschaffenheit". Tradução alternativa: "constituição".

${ }^{7}$ No original: "beilege". Talvez não seja aqui o caso de traduzir por "atribuir", embora o verbo alemão também tenha este significado. Alternativamente poder-se-ía pensar em "conferir".
} 


\section{Advertência preliminar}

A dedução das categorias está ligada a tantas dificuldades e força a penetrar tão fundo nos fundamentos primeiros da possibilidade de nosso conhecimento em geral que eu, a fim de evitar a vastidão de uma teoria completa e ainda assim nada descuidar numa investigação tão necessária, achei aconselhável mais preparar o leitor do que instruí-lo mediante os quatro números seguintes, e de só na terceira seção, a qual segue imediatamente depois, apresentar sistematicamente a elucidação destes elementos do entendimento. Devido a isso, até lá o leitor talvez não se deixará repelir pela obscuridade inicialmente inevitável num caminho nunca dantes trilhado, mas que, como espero, deve ser esclarecida em compreensão completa na refererida seção.

\section{1 - Da síntese da apreensão na intuição}

Que nossas representações surjam de onde quiserem, sejam efetuadas pela influência de coisas externas ou por causas internas, tenham surgido a priori ou empiricamente como fenômenos, ainda assim pertencem, [A 99] como modificações da mente, ao sentido interno, e como tais todos os nossos conhecimentos estão ainda assim submetidos, em última instância, à condição formal do sentido interno, a saber, ao tempo, como [aquele] no qual todos tem que ser ordenados, conectados e postos em relações. Isto é uma observação geral que precisa absolutamente ser tomada como o fundamento daquilo que se segue.

Cada intuição contém em si um múltiplo que ainda assim não seria representado como um tal [múltiplo] se a mente não distinguisse o tempo na sucessão das impressões umas às outras: pois enquanto contida num instante cada representação não pode ser outra coisa senão unidade absoluta. Para que deste múltiplo se faça agora unidade da intuição (como por exemplo na representação do espaço) é necessário primeiro um percurso da multiplicidade e então a contração dele $^{8}$, ato este que chamo de síntese $d a$ apreensão por estar dirigido diretamente à intuição, a qual bem que oferece um múltiplo, mas jamais pode efetuá-lo como um tal [múltiplo], e isto contido numa representação, sem que aí ocorra uma síntese.

\footnotetext{
${ }^{8}$ No original: "das Durchlaufen der Mannigfaltigkeit und denn die Zusammennehmung desselben". Na edição de Weischedel lê-se um "denn" consecutivo onde KrV Schmidt imprime um "dann" temporal. 0 termo "Durchlaufen" é a substantivação pura e simples do verbo, ao passo que "Zusammennehmung" é derivado do verbo correspondente. A elegância do vernáculo ditou traduzir em ambos os casos pelos substantivos oriundos dos verbos em questão.
} 
Esta síntese da apreensão também tem que ser exercida a priori, isto é, com vistas às representações que não são empíricas. Pois sem ela não poderíamos ter a priori nem as representações do espaço nem do tempo, já que estas só [A 100] podem ser geradas pela síntese do múltiplo oferecido pela sensibilidade em sua receptividade originária. Portanto temos uma síntese pura da apreensão.

\section{2 - Da síntese da reprodução na imaginação}

Na verdade é meramente empírica a lei segundo a qual representações que freqüentemente vieram acompanhadas umas das outras ou se seguiram umas às outras terminam por se associar entre si e, mediante tal, por estabelecer uma conexão segundo a qual uma destas representações produz, segundo uma regra constante, uma passagem da mente a uma outra [representação] também sem a presença do objeto. Mas esta lei da reprodução pressupõe que os próprios fenômenos estejam submetidos efetivamente a uma tal regra e que ocorra, de acordo com certas regras, um acompanhamento ou uma sucessão no múltiplo das suas representações; pois sem isto a nossa imaginação empírica jamais receberia a fazer algo conforme à sua faculdade, permanecendo portanto oculta no interior da mente como uma faculdade morta e desconhecida de nós mesmos. Se o cinabre fosse ora vermelho ora negro, ora leve ora pesado, se um homem se transformasse ora nesta forma animal ora naquela, se no dia mais longo do ano a [A 101] terra estivesse coberta ora de frutos ora de neve e gelo, a minha imaginação empírica nem chegaria a ter a oportunidade de, quando da representação da cor vermelha, captar em pensamento o cinabre pesado, ou se uma certa palavra fosse aplicada ora a esta coisa ora àquela, ou também a mesma coisa denominada ora assim ora assado, sem que aí predominasse uma certa regra à qual os fenômenos já não estivessem submetidos por si mesmos, não poderia ocorrer qualquer síntese empírica da reprodução.

Por isso tem que haver algo que torne ele mesmo possível esta reprodução dos fenômenos pelo fato de ser o fundamento a priori de uma unidade sintética necessária dos mesmos. Disto, contudo, logo nos damos conta quando acudimos que fenômenos não são coisas em si mesmas, mas sim o mero jogo de nossas representações, as quais são, ao fim e ao cabo, determinações do sentido interno. Ora, se pudermos mostrar que mesmo as nossas intuições a priori as mais puras não proporcionam conhecimento algum senão na medida em que contenham uma ligação do múltiplo tal que ela torne possível uma síntese pervasiva da reprodução, então esta síntese da imaginação está fundada a priori em princípios também antes de toda a 
experiência, e é preciso assumir uma síntese transcendental pura da mesma que subjaza, ela mesma, à possibilidade de toda experiência (como a que pressupõe necessariamente a reprodutibilidade [A 102] dos fenômenos). Ora, é manifesto que, quando traço uma linha em pensamento ou quero pensar o tempo de um meio-dia ao outro ou também apenas representar-me um certo número, tenho primeiro que captar em pensamento necessariamente uma destas múltiplas representações após a outra. Mas se eu sempre perdesse do pensamento a [representação] precedente (as primeiras partes da linha, as partes precedentes do tempo ou as unidades representadas sucessivamente) e se eu não as reproduzisse ao progredir até as seguintes, então jamais poderia surgir uma representação toda nem qualquer dos pensamentos mencionados previamente, e nem mesmo as representações fundamentais primeiras e mais puras do espaço e do tempo.

A síntese da apreensão está portanto inseparavelmente ligada à síntese da reprodução. E já que aquela perfaz o fundamento transcendental da possibilidade de todo conhecimento em geral (não apenas do empírico, mas também do puro a priori), a síntese reprodutiva da imaginação faz parte dos atos transcendentais da mente, e em consideração aos mesmos queremos chamar esta faculdade também de faculdade transcendental da imaginação.

\section{[A 103] 3 - Da síntese do reconhecimento [Rekognition] no conceito}

Sem consciência de que aquilo que pensamos é precisamente o mesmo que aquilo que pensáramos um momento antes, seria em vão toda reprodução na série das representações. Pois no estado de agora haveria uma representação nova que de modo algum pertenceria ao ato pelo qual ela deveria ter sido gerada paulatinamente, e o múltiplo da mesma [representação] jamais perfaria um todo por carecer da unidade que só a consciência pode lhe proporcionar. Se ao contar eu esqueço que as unidades que agora tenho em mente foram paulatinamente acrescentadas por mim uma à outra, eu não conheceria a produção do conjunto por este acréscimo sucessivo de um a um, portanto também não o número; pois este conceito consiste simplesmente na consciência desta unidade da síntese.

O termo conceito poderia já por si mesmo dar-nos as instruções para esta observação. Pois esta uma consciência é o que une numa representação o múltiplo que foi intuído paulatinamente e então também reproduzido. Esta consciência pode com freqüência ser somente fraca, de modo que a conectamos com a produção da representação só no efeito, mas não no próprio ato, isto é, imediatamente [A 104]: mas a despeito destas diferenças uma consciência tem sempre que ser encontrada, mesmo que lhe falte a 
clareza saliente, e sem a mesma [consciência] são totalmente impossíveis conceitos e com eles o conhecimento de objetos.

E aqui é então necessário dar a entender o que se quer dizer com a expressão de um objeto das representações. Dissemos acima que fenômenos nada mais são senão representações sensíveis que em si, de maneira exatamente a mesma, não devem ser considerados como objetos (fora da capacidade representativa). Mas o que se entende quando se fala de um objeto correspondente ao e portanto também distinto do conhecimento? É fácil darse conta que este objeto tem que ser pensado só como algo em geral $=\mathrm{X}$, pois afora o nosso conhecimento não temos nada que possamos contrapor a este conhecimento como lhe correspondendo.

Achamos todavia que o nosso pensamento da referência de todo conhecimento ao seu objeto traz consigo algo de necessidade, a saber que este [objeto] é considerado como aquilo que está contra, que nossos conhecimentos não sejam determinados de qualquer jeito e a bel prazer, mas [que sejam determinados] a priori de uma certa maneira, pois na medida em que devem se referir a um objeto também tem que concordar necessariamente entre si com referência a ele, [A 105] isto é, possuir aquela unidade que perfaz o conceito de um objeto.

Pelo fato de estarmos às voltas apenas com o múltiplo de nossas representações e de aquele $\mathrm{X}$ que lhes corresponde (o objeto) nada ser para nós porque deve ser algo distinto de todas as nossas representações, está claro, contudo, que a unidade que o objeto torna necessária não pode ser outra coisa senão a unidade formal da consciência na síntese do múltiplo das representações. Dizemos então que conhecemos o objeto quando tivermos efetivado unidade sintética no múltiplo da intuição. Mas esta [unidade] é impossível se a intuição não pôde ser produzida por uma função de síntese segundo uma regra [, uma função] tal que torne necessária a priori a reprodução do múltiplo e possível um conceito no qual este [múltiplo] seja reunido. Assim, pensamo-nos um triângulo como objeto ao estarmos conscientes da composição de três linhas retas segundo uma regra segundo a qual uma tal intuição pode sempre ser apresentada. Ora, esta unidade da regra determina todo o múltiplo e o restringe a condições que tornam possível a unidade da apercepção, e o conceito desta unidade é a representação do objeto $=\mathrm{X}$ que penso mediante os predicados pensados de um triângulo.

[A 106] Todo conhecimento requer um conceito, seja este tão imperfeito ou tão obscuro quanto se queira: mas segundo a sua forma ele é sempre algo universal e que serve de regra. Assim, o conceito de corpo serve, segundo a unidade do múltiplo que é pensado por ele, de regra para o nosso 
conhecimento de fenômenos externos. Mas ele só pode ser uma regra das intuições pelo fato de representar, quanto a fenômenos dados, a reprodução necessária do múltiplo delas, portanto a unidade sintética na consciência delas. Assim, o conceito de corpo torna necessária, quanto à percepção de algo fora de nós, a representação de extensão e, com ela, a de impenetrabilidade, de figura etc.

A toda necessidade sempre subjaz uma condição transcendental. Logo, também tem que ser encontrado um fundamento transcendental da unidade da consciência na síntese do múltiplo de todas as nossas intuições, portanto também dos conceitos dos objetos em geral, conseqüentemente também de todos os objetos da experiência, [fundamento] sem o qual seria impossível pensar qualquer objeto para as nossas intuições: pois este [objeto] nada mais é senão o algo do qual o conceito expressa uma tal necessidade da síntese.

Esta condição transcendental e originária não é nenhuma outra senão a apercepção transcendental. [A 107] A consciência de si mesmo segundo as determinações de nosso estado quando da percepção interna é meramente empírica, sempre mutável, não podendo haver qualquer si-mesmo que está ou permanece $\left[{ }^{9}\right]$ neste fluxo de fenômenos internos, e ela é comumente chamada de sentido interno ou de apercepção empírica. Aquilo que necessariamente deve ser representado como idêntico numericamente não pode ser pensado como um tal [idêntico] por dados empíricos. Tem que haver uma condição, antecedendo a toda experiência e tornando esta mesma [experiência] possível, que deve fazer valer uma tal pressuposição transcendental.

Ora, não podem ocorrer em nós quaisquer conhecimentos, qualquer conexão e unidade dos mesmos entre si, sem aquela unidade da consciência que precede a todos os dados das intuições e em relação à qual é unicamente possível toda representação de objetos. Esta consciência pura imutável, originária eu quero agora chamar de apercepção transcendental. Que merece este nome já fica claro do fato de que mesmo a unidade objetiva a mais pura, a saber, a dos conceitos a priori (espaço e tempo), só é possível por referência das intuições a ela. A unidade numérica desta apercepção está portanto a priori tão na base $\left[{ }^{10}\right]$ de todos os conceitos quanto a multiplicidade do espaço e do tempo na das intuições da sensibilidade.

\footnotetext{
${ }^{9}$ No original: "kein stehendes oder bleibendes Selbst". O pronome reflexivo substantivado é difícil de traduzir em português, correspondendo perfeitamente ao inglês "self". Além disso, é uma pena que o particípio presente do verbo estar já esteja, em português, indelevelmente associado ao prosaico móvel que serve para guardar livros. A solução adotada parece preferivel a "o si-mesmo imóvel e permanente" ou algo semelhante.

10 Cf. supra nota 2.
} 
[A 108] É precisamente esta unidade transcendental da apercepção que faz, de todos os possíveis fenômenos que podem estar juntos numa experiência, uma interconexão de todas estas representações segundo leis. Pois esta unidade da consciência seria impossível se, no conhecimento do múltiplo, a mente não pudesse tornar-se consciente da identidade da função pela qual liga o mesmo [múltiplo] sinteticamente num conhecimento. Portanto, a consciência necessária e originária da identidade de si mesmo é simultaneamente uma consciência de uma unidade igualmente necessária da síntese de todos os fenômenos segundo conceitos, isto é, segundo regras que não só os tornam reprodutíveis necessariamente, mas com isso também destinam $\left[{ }^{11}\right]$ à sua intuição um objeto, isto é, o conceito de algo no qual estejam necessariamente interconectados: pois seria impossível para a mente pensar a identidade de si mesma na multiplicidade de suas representações, e isto a priori, se não tivesse diante dos olhos a identidade de seu ato, o qual submete toda síntese da apreensão (que é empírica) a uma unidade transcendental e torna primeiro possível a sua interconexão segundo regras a priori. Doravante também poderemos definir, de um modo em geral mais correto, os nossos conceitos de um objeto. Todas as representações têm, enquanto representações, o seu objeto, e podem elas mesmas ser por sua vez objetos de outras representações. Fenômenos são os únicos objetos [A 109] que nos podem ser dados imediatamente, e aquilo que neles se refere imediatamente ao objeto chama-se intuição. Porém estes fenômenos não são coisas em si mesmas, mas eles mesmos apenas representações que têm por sua vez o seu objeto, o qual portanto não pode mais ser intuído por nós e que talvez possa, por isto, ser chamado de objeto $=\mathrm{X}$ não-empírico, isto é, transcendental.

O conceito puro deste objeto transcendental (que efetivamente é sempre o mesmo $=\mathrm{X}$ em todos os nossos conhecimentos) é aquilo que, em todos os nossos conceitos empíricos, pode proporcionar em geral referência a um objeto, ou seja, realidade objetiva. Ora, este conceito não pode conter intuição determinada alguma, e portanto não dirá respeito a outra coisa senão àquela unidade que tem que ser encontrada num múltiplo do conhecimento na medida em que está referido a um objeto. Mas esta referência nada mais é senão a unidade necessária da consciência, portanto também da síntese do múltiplo pela função em comum da mente de o ligar numa representação. Visto que esta unidade precisa ser considerada como

$11 \mathrm{Na}$ presente passagem é difícil distinguir entre os dois significados do verbo "bestimmen", o de "determinar" e o de "destinar". A opção no texto foi ditada por tentar-se reproduzir no vernáculo a mesma regência que ocorre no texto alemão. 
necessária a priori (pois senão o conhecimento seria sem objeto), a referência a um objeto transcendental, isto é, a realidade objetiva de nosso conhecimento empírico, repousará sobre a [A 110] lei transcendental de que todos os fenômenos, na medida em que por eles nos devam ser dados objetos, tem que estar sob regras a priori da unidade sintética dos mesmos, [regras] segundo as quais é unicamente possível a sua relação na intuição empírica, isto é, [a lei transcendental] de que eles tanto têm que estar, na experiência, sob as condições da unidade necessária da apercepção quanto, na mera intuição, sob as condições formais do espaço e do tempo, e de que só por aquelas [regras] torna-se primeiro possível todo conhecimento.

\section{4 - Explicação preliminar da possibilidade das categorias, como conhecimentos a priori}

É apenas uma a experiência na qual todas as percepções são representadas como [estando] numa interconexão pervasiva e de acordo com leis, do mesmo modo que é apenas um o espaço e o tempo no qual ocorrem todas as formas do fenômeno e toda relação de ser ou de não-ser. Quando se fala de diversas experiências, trata-se apenas de outras tantas percepções na medida em que estas pertencem a uma e mesma experiência geral. Pois a unidade sintética e pervasiva das percepções perfaz precisamente a forma da experiência, e ela nada mais é senão a unidade sintética dos fenômenos segundo conceitos.

[A 111] A unidade da síntese segundo conceitos empíricos seria totalmente contingente e, se estes não se fundassem num fundamento transcendental da unidade, seria possível que um turbilhão de fenômenos enchesse a nossa alma sem que disto jamais pudesse resultar, não obstante, experiência. Então ficaria também suprimida qualquer referência do conhecimento a objetos, pois faltar-lhe-ía a conexão segundo leis necessárias e universais, seria portanto intuição sem pensamento, é verdade, mas jamais conhecimento, logo seria o mesmo que nada para nós.

As condições a priori de uma experiência possível em geral são simultaneamente condições de possibilidade dos objetos da experiência. Agora eu afirmo que as categorias há pouco mencionadas nada mais são senão as condições do pensar numa experiência possível, tal como espaço e tempo contêm as condições da intuição para exatamente a mesma [experiência]. Portanto aquelas [categorias] também são conceitos fundamentais para em geral pensar objetos referentes aos fenômenos, e têm portanto validade objetiva a priori, o que é aquilo que queríamos propriamente saber. 
A possibilidade contudo, até mesmo a necessidade destas categorias repousa sobre a referência da sensibilidade toda, e com ela também de todos os fenômenos possíveis, à apercepção originária, na qual tudo tem que estar necessariamente de acordo com as condições da unidade pervasiva da autoconsciência, isto é, [A 112] sob as funções universais da síntese, a saber, da síntese segundo conceitos, como [aquela] unicamente na qual a apercepção pode provar a priori a sua identidade necessária e pervasiva. Assim, o conceito de uma causa não é outra coisa senão uma síntese (daquilo que se segue numa sucessão temporal com outros fenômenos) segundo conceitos, e sem semelhante unidade, a qual tem a sua regra a priori e submete a si os fenômenos, não seria encontrada unidade universal e pervasiva, portanto necessária, da consciência no múltiplo das percepções. Mas então estas [percepções] também não pertenceriam a experiência alguma, conseqüentemente seriam sem objeto e nada mais senão um jogo cego das representações, isto é, menos que um sonho.

Todas as tentativas de derivar da experiência aqueles conceitos puros do entendimento e de atribuir-lhes uma origem meramente empírica são portanto totalmente presunçosas e vãs. Não quero nem mencionar que, por exemplo, o conceito de uma causa traz consigo o traço de uma necessidade que experiência alguma pode dar, a qual nos ensina, é bem verdade, que a um fenômeno se segue habitualmente uma outra coisa, mas não que tenha necessariamente que se seguir a ele, nem que se possa dele como condição inferir, a priori e de modo totalmente universal, a sucessão. Mas e aquela regra empírica da associação que é preciso assumir sem exceção quando se diz que, na sucessão dos eventos, [A 113] tudo está de tal modo sob regras que jamais acontece algo que não tenha sido precedido por algo ao qual sempre se segue, sobre o que repousa, pergunto eu, isto como uma lei da natureza e como é propriamente possível esta associação? $O$ fundamento da possibilidade da associação do múltiplo, na medida em que jaz no objeto, chama-se de afinidade do múltiplo. Pergunto, portanto, como vos tornais concebível a afinidade pervasiva dos fenômenos (pela qual estão sob leis constantes e têm que estar subsumidos a elas)?

Segundo os meus princípios, ela é concebível muito bem. Todos os fenômenos possíveis pertencem, enquanto representações, à autoconsciência possível toda. Mas desta, enquanto uma representação transcendental, a identidade numérica é inseparável e certa a priori, pois nada pode entrar no conhecimento sem ser mediante esta apercepção originária. Já que agora esta identidade precisa necessariamente entrar na síntese de todo o múltiplo dos fenômenos na medida em que ela deve tornar-se conhecimento empírico, os fenômenos estão submetidos a priori a condições com as quais a sua síntese 
(da apreensão) tem que estar pervasivamente de acordo. Ora, a representação de uma condição universal segundo a qual um certo múltiplo pode ser posto (portanto de maneira igual) chama-se de regra e, se ele tem que ser posto assim, de lei. Logo, todos os fenômenos estão numa conexão pervasiva segundo leis [A 114] necessárias, e portanto numa afinidade transcendental da qual a [afinidade] empírica é a mera conseqüência.

Que a natureza deva orientar-se por nosso fundamento subjetivo da apercepção e até mesmo depender dele com respeito à sua conformidade a leis, soa estranho e bem a contra-senso. Mas caso se considere que esta natureza nada é em si senão um complexo de fenômenos, portanto não uma coisa em si, mas apenas um conjunto de representações da mente, então não será de admirar-se que apenas na faculdade radical de todo nosso conhecimento, a saber, na apercepção transcendental, se a veja naquela unidade unicamente em nome da qual pode chamar-se de objeto de toda experiência possível, isto é, de natureza; e que também precisamente por isso podemos conhecer a priori, portanto também como necessária, esta unidade, coisa que teríamos que deixar pelo caminho se ela fosse dada em si independente das primeiras fontes de nosso pensar. Pois então eu não saberia onde deveríamos ir buscar as proposições sintéticas de uma tal unidade universal da natureza, já que num tal caso precisaríamos tomá-las de empréstimo dos objetos da natureza. E como isso só poderia ocorrer empiricamente, não se poderia tirar daí nenhuma outra unidade senão uma unidade meramente contingente, mas que nem de longe alcança a interconexão necessária que se quer dizer quando se a chama de natureza.

\section{[A 115] Dedução dos Conceitos Puros do Entendimento}

\section{Terceira seção}

$\mathrm{Da}$ relação do entendimento a objetos em geral e da possibilidade de os conhecer a priori

Aquilo que expusemos separada e individualmente na seção anterior queremos agora apresentar unificadamente e em interconexão. São três as fontes subjetivas de conhecimento sobre as quais repousa a possibilidade de uma experiência em geral e o conhecimento dos objetos da mesma: sentido, imaginação e apercepção; cada uma delas pode ser considerada empiricamente, a saber, na aplicação a fenômenos dados, mas todas também são elementos ou bases a priori que tornam propriamente possível este uso empírico. O sentido representa os fenômenos empiricamente na percepção, a 
imaginação na associação (e reprodução), a apercepção na consciência empírica da identidade destas representações reprodutivas com os fenômenos pelos quais são dadas, portanto no reconhecimento [Rekognition].

Mas à percepção toda subjaz a priori a intuição pura (com respeito a ela [percepção] como representação a forma da intuição interna, o tempo), à associação a [A 116] síntese pura da imaginação e à consciência empírica a apercepção pura, isto é, a identidade pervasiva de si mesmo junto a todas as representações possíveis.

Se quisermos agora perseguir o fundamento interno desta conexão das representações até aquele ponto em que todas têm que confluir a fim de primeiro aí obter unidade de conhecimento para uma experiência possível, temos que começar da apercepção pura. Todas as intuições nada são para nós e não nos dizem minimamente respeito se não puderem ser acolhidas na consciência, influam nela direta ou indiretamente, e unicamente por ela o conhecimento é possível. Somos conscientes a priori da identidade pervasiva de nós mesmos com vistas a todas as representações que alguma vez possam pertencer ao nosso conhecimento, [e isto] como uma condição necessária da possibilidade de todas as representações (pois estas só representam algo em mim pelo fato de, com tudo o mais, pertencerem a uma consciência, portanto de terem pelo menos que poder ser conectadas nela). Este princípio está assente a priori e pode ser chamado de princípio transcendental da unidade de todo múltiplo de nossas representações (portanto também na intuição). Ora, a unidade do múltiplo num sujeito é sintética, portanto a apercepção pura fornece um princípio [A 117] da unidade sintética do múltiplo em toda intuição possível".

\footnotetext{
* Preste-se bem atenção nesta proposição, que é de grande importância. Todas as representações possuem uma referência necessária a uma consciência empírica possível: pois se não a tivessem e se fosse inteiramente impossível tornar-se consciente delas, isto equivaleria a dizer que elas de modo algum existem. Toda consciência empírica tem, contudo, uma referência necessária a uma consciência transcendental (que precede a toda experiência particular), a saber, à consciência de mim mesmo como a apercepção originária. É portanto absolutamente necessário que, em meu conhecimento, toda consciência pertença a uma consciência (de mim mesmo). Ora, aqui há uma unidade sintética do múltiplo (da consciência) que é conhecida a priori e constitui, precisamente deste modo, o fundamento para proposições sintéticas a priori que dizem respeito ao pensar puro, tal como espaço e tempo [dizem respeito] a proposições tais que concernem a forma da mera intuição. A proposição sintética de que toda consciência empírica diversa tem que estar ligada numa autoconsciência una é o princípio sintético e absolutamente primeiro de nosso pensar em geral. Não se deve contudo deixar de cuidar que a simples representação eu é a consciência transcendental com referência a todas as demais [representações] (cuja unidade coletiva ela torna possível). Que esta representação seja agora clara (consciência empírica) ou obscura, isto não importa aqui, nem mesmo a sua realidade importa; mas a possibilidade da forma lógica de todo conhecimento repousa necessariamente sobre a relação com esta apercepção como uma faculdade.
} 
[A 118] Esta unidade sintética, no entanto, pressupõe ou inclui uma síntese, e se aquela deve ser necessária a priori, a última também precisa ser uma síntese a priori. Portanto, a unidade transcendental da apercepção referese à síntese pura da imaginação como uma condição a priori da possibilidade de toda composição do múltiplo num conhecimento. Mas só pode ocorrer a priori a síntese produtiva da imaginação, pois a reprodutiva repousa sobre condições da experiência. Logo, o princípio da unidade necessária da síntese (produtiva) pura da imaginação antes da apercepção é o fundamento da possibilidade de todo conhecimento, particularmente da experiência.

Ora, a síntese do múltiplo na imaginação é por nós chamada de transcendental quando, sem distinção das intuições, incide a priori em nada senão meramente na ligação do múltiplo, e a unidade desta síntese é chamada de transcendental quando é representada como necessária a priori com referência à unidade originária da apercepção. Por esta última subjazer agora à possibilidade de todo conhecimento, a unidade transcendental da síntese da imaginação é a forma pura de todo conhecimento possível, pela qual, portanto, tem que ser representados a priori todos os objetos de experiência possível.

[A 119] A unidade da apercepção com referência à síntese da imaginação é o entendimento, e esta mesma unidade, com referência à síntese transcendental da imaginação, é o entendimento puro. No entendimento há, portanto, conhecimentos puros a priori que contêm a unidade necessária da síntese pura da imaginação com vistas a todos os fenômenos possíveis. Mas isto são as categorias, isto é, conceitos puros do entendimento, conseqüentemente a capacidade cognitiva empírica do homem contem necessariamente um entendimento que se refere a todos os objetos dos sentidos, embora só mediante a intuição e a síntese da mesma por imaginação, sob os quais $\left[{ }^{12}\right]$ portanto estão todos os fenômenos como dados para uma experiência possível. Já que esta referência dos fenômenos à experiência possível é igualmente necessária (pois sem esta [referência] não obteríamos conhecimento algum por eles, e eles portanto não nos diriam respeito algum), segue-se que o entendimento puro, mediante as categorias, é um princípio sintético e formal de todas as experiências, e que os fenômenos têm uma referência necessária ao entendimento.

12 Lendo com Weischedel "unter welchen", onde o pronome relativo plural pode referir-se tanto a "categorias" quanto a "conceitos puros do entendimento". Erdmann, emendando o plural em singular, leu "unter welchem", caso em que o pronome relativo passa a se referir a "entendimento" (cf. KrV Schmidt nota ad loc.). 
Agora queremos pôr diante dos olhos a interconexão necessária do entendimento com os fenômenos mediante as categorias começando de baixo, ou seja, do empírico. A primeira coisa que nos [A 120] é dada é fenômeno, que é chamado de percepção quando está ligado à consciência (sem a relação a uma consciência pelo menos possível o fenômeno jamais poder-se-ía tornar um objeto de conhecimento para nós e portanto nada seria para nós, e por não ter em si mesmo realidade objetiva alguma e existir apenas no conhecimento nada seria em parte alguma). Mas porque cada fenômeno contém um múltiplo, sendo que na mente, portanto, diversas percepções são encontradas em si dispersas e isoladas, é preciso uma ligação das mesmas que elas não podem ter no próprio sentido. Logo, há em nós uma faculdade ativa da síntese deste múltiplo, a qual chamamos de imaginação e cuja ação exercida imediatamente nas percepções eu chamo de apreensão $^{* *}$. Pois a imaginação deve verter o múltiplo da intuição em uma imagem; antes disto ela tem portanto que receber em sua atividade as impressões, isto é, apreender.

[A 121] É claro, todavia, que mesmo esta apreensão do múltiplo ainda não produziria sozinha imagem alguma ou interconexão alguma das impressões se não houvesse aí um fundamento subjetivo para que uma percepção, da qual a mente tivesse passado a outra, fosse chamada a se juntar às subseqüentes e assim apresentadas séries inteiras das mesmas, isto é, [se não houvesse aí] uma faculdade reprodutiva da imaginação que também é tão somente empírica.

Mas devido ao fato de que não surgiria interconexão determinada alguma das representações, portanto conhecimento algum, mas sim meramente um montão de representações sem regra se estas, tão logo se encontrassem, passassem a se reproduzir umas às outras sem distinção, a reprodução delas tem que ter uma regra segundo a qual uma representação estabelece, na imaginação, uma ligação antes com esta que com aquela [representação]. Este fundamento empírico e subjetivo da reprodução segundo regras é chamado de associação das representações.

Ora, se esta unidade da associação também não tivesse um fundamento objetivo, de sorte que fosse impossível[ $\left.{ }^{13}\right]$ que fenômenos fossem apreendidos

\footnotetext{
** Que a imaginação é um ingrediente necessário da própria percepção, eis algo em que ainda nenhum psicólogo pensou. Isto se dá em parte porque esta faculdade foi restringida só a reproduções, em parte porque se acreditou que os sentidos não nos forneciam unicamente impressões, mas chegavam também a compô-las e a proporcionar imagens dos objetos, o que sem dúvida requer, afora a receptividade das impressões, ainda algo mais, a saber, uma função de síntese das mesmas.

${ }^{13}$ Sic no texto impresso de Kant. Vaihinger corrige, de acordo com o sentido da frase, para "possível" (cf. KrV Schmidt nota ad loc.).
} 
pela imaginação de outro modo que sob a condição de uma unidade sintética possível desta apreensão, então também seria algo totalmente contingente que os fenômenos se conformassem a uma interconexão dos conhecimentos humanos. Pois embora tivéssemos a faculdade de associar percepções, continuaria em si [A 122] inteiramente indeterminado e contingente se elas também seriam associáveis; e no caso de que o não fossem, seria possível uma porção de percepções, e talvez também uma sensibilidade toda, em que se encontraria muita consciência empírica em minha mente, mas separadamente e sem que pertencesse a uma consciência de mim mesmo, o que é, contudo, impossível. Pois somente pelo fato de eu computar todas as percepções [como pertencentes] a uma consciência (da apercepção originária) posso, quando de todas as percepções, dizer que sou consciente delas. Portanto, tem que haver um fundamento objetivo, isto é, compreensível a priori antes de todas as leis empíricas da imaginação, sobre o qual repouse a possibilidade, até mesmo a necessidade de uma lei que se estenda por todos os fenômenos, a saber, leve a encará-los sem exceção como dados tais dos sentidos que sejam em si associáveis e submetidos a regras universais de uma conexão pervasiva na reprodução. A este fundamento objetivo de toda associação dos fenômenos eu chamo de afinidade dos mesmos. Não podemos encontrá-lo em parte alguma senão no princípio da unidade da apercepção, com vistas a todos os conhecimentos que me devem pertencer. Segundo este princípio, absolutamente todos os fenômenos tem que chegar à mente ou ser apreendidos de maneira tal que concordem com a unidade da apercepção, o que seria impossível sem unidade sintética na conexão deles, a qual portanto também é objetivamente necessária.

[A 123] A unidade objetiva de toda consciência (empírica) numa consciência (da apercepção originária) é portanto a condição necessária até mesmo de toda percepção possível, e a afinidade de todos os fenômenos (próxima ou remota) é uma conseqüência necessária de uma síntese na imaginação que está fundada a priori em regras.

Portanto, a imaginação também é uma faculdade de uma síntese a priori, pelo que lhe damos o nome de imaginação produtiva, e na medida em que, com vistas a todo o múltiplo do fenômeno, tem como seu propósito nada mais senão a unidade necessária na síntese do mesmo, pode ser chamada de função transcendental da imaginação. Por conseguinte, na verdade causa estranheza, mas não obstante faz sentido a partir do dito até aqui, que só mediante esta função transcendental da imaginação torna-se possível até mesmo a afinidade dos fenômenos, com ela a associação e por esta finalmente a reprodução segundo leis, 
conseqüentemente a própria experiência, pois sem ela não confluiriam numa experiência quaisquer conceitos de objetos.

Pois o eu que está e permanece[ $\left.{ }^{14}\right]$ (o da apercepção pura) constitui o correlato de todas as nossas representações na medida em que é simplesmente possível tornar-se consciente delas, e tanto toda consciência pertence a uma apercepção pura que tudo abrange quanto toda intuição [A 124] sensível pertence como representação a uma intuição interna pura, a saber, ao tempo. Ora, esta apercepção é o que precisa ser acrescentado à imaginação pura para tornar intelectual a sua função. Com efeito, em si mesma a síntese da imaginação, embora exercida a priori, ainda assim é sempre sensível, pois ela só liga o múltiplo tal como ele aparece na intuição, por exemplo a figura de um triângulo. Mas pela relação do múltiplo à unidade da apercepção podem ser estabelecidos conceitos que pertencem ao entendimento, os quais, contudo, só mediante a imaginação podem ser estabelecidos com referência à intuição sensível.

Temos portanto uma imaginação pura como uma faculdade fundamental da alma humana que subjaz a priori a todo o conhecimento. Por seu intermédio colocamos em ligação o múltiplo da intuição de um lado, e de outro lado [o ligamos] com a condição da unidade necessária da apercepção pura. Ambas as pontas extremas, a saber, sensibilidade e entendimento, tem que estar necessariamente interconectadas por intermédio desta função transcendental da imaginação, pois senão ambos dariam muito bem fenômenos, mas não objetos de um conhecimento empírico, portanto experiência alguma. A experiência efetiva, a qual consiste da apreensão, da associação (da reprodução), finalmente do reconhecimento dos fenômenos, contem, neste último [A 125] e supremo (dos elementos meramente empíricos da experiência), conceitos que tornam possível a unidade formal da experiência e com ela toda validade objetiva (verdade) do conhecimento empírico. Ora, estes fundamentos do reconhecimento do múltiplo, na medida em que dizem respeito meramente à forma de uma experiência em geral, são aquelas categorias. Nelas funda-se portanto toda unidade formal na síntese da imaginação, e mediante esta também de todo uso $\left[{ }^{15}\right]$ empírico da mesma (no reconhecimento, reprodução, associação, apreensão) descendo até os fenômenos, pois é só mediante aqueles elementos que estes [fenômenos] podem pertencer ao conhecimento e em geral à nossa consciência, portanto a nós mesmos.

Portanto nós mesmos introduzimos nos fenômenos a ordem e regularidade que chamamos de natureza, e também não a poderíamos encontrar

\footnotetext{
${ }^{14} \mathrm{Cf}$. supra nota 9. Em italiano o passus é perfeitamente tradutível: "Il io permanente e stante".

15 Lendo com Weischedel a expressão no genitivo. Adickes muda a expressão para o nominativo, e neste caso seria de traduzir "também todo o uso" (cf. KrV Schmidt nota ad loc.).
} 
neles não a tivéssemos nós ou a natureza de nossa mente aí posta originariamente. Pois esta unidade da natureza deve ser uma unidade necessária, ou seja, certa a priori, da conexão dos fenômenos. Mas como é que deveríamos conseguir encaminhar a priori uma unidade sintética se nas fontes originárias de conhecimento de nossa mente não estivessem contidos a priori os fundamentos subjetivos de uma tal unidade, e se estas condições subjetivas não fossem ao mesmo tempo objetivamente válidas ao serem os fundamentos [A 126] da possibilidade de em geral conhecer um objeto na experiência.

Acima explicamos o entendimento de maneira variegada: por uma espontaneidade do conhecimento (em oposição à receptividade da sensibilidade), por uma faculdade de pensar, ou também uma faculdade dos conceitos, ou também dos juízos, explicações que, examinadas à luz do dia, desembocam em uma só. Agora podemos caracterizá-lo como a faculdade das regras. Esta caracterização é mais frutífera e se aproxima mais da essência dele. Sensibilidade dá-nos formas (da intuição), o entendimento, no entanto, regras. A todo momento ele está ocupado em vasculhar os fenômenos com o propósito de neles descobrir alguma regra. Regras, na medida em que são objetivas (portanto necessariamente apensas ao conhecimento do objeto), são chamadas de leis. Embora consigamos aprender muitas leis por experiência, elas são apenas determinações particulares de leis ainda maiores, dentre as quais as supremas (sob as quais estão todas as demais) procedem a priori do próprio entendimento e não são emprestadas da experiência, mas tem que proporcionar aos fenômenos a sua conformidade a leis e precisamente por isto tornar possível experiência. Portanto, o entendimento não é meramente uma faculdade de se fazer regras por comparação dos fenômenos, ele mesmo é a legislação para a natureza, ou seja, sem entendimento em parte alguma haveria natureza, isto é, unidade sintética [A 127] do múltiplo dos fenômenos segundo regras, pois fenômenos não podem, como tais, ocorrer fora de nós, mas só existem em nossa sensibilidade. Esta $\left[{ }^{16}\right]$ todavia, como objeto de conhecimento em uma experiência, com tudo que ela possa conter, é possível só na unidade da apercepção. A unidade da apercepção, porém, é o fundamento transcendental da conformidade necessária a leis [que é própria] de todos os fenômenos numa experiência. Precisamente a mesma unidade da apercepção com vistas a um múltiplo de representações (a saber, para determiná-lo a partir de uma única [representação]) é a regra e a faculdade destas regras o entendimento. Logo, todos os fenômenos estão, como experiências possíveis, igualmente a priori no entendimento e recebem dele a

\footnotetext{
${ }^{16}$ Vaihinger substitui o "diese" ("esta") inicial desta oração por "jene" ("aquela"), e Erdmann refere "diese" a "natureza" (cf. KrV Schmidt nota ad loc.).
} 
sua possibilidade formal, assim como estão, como meras intuições, na sensibilidade e são unicamente possíveis, quanto à forma, pela mesma.

Por mais que soe exagerado, que soe um contra-senso dizer que o próprio entendimento é a fonte das leis da natureza e portanto da unidade formal da natureza, tão correta é não obstante uma tal afirmação e tão adequada a seu objeto, a saber, à experiência. É claro que leis empíricas de modo algum podem, como tais, derivar do entendimento puro a sua origem, tampouco quanto a multiplicidade imensurável dos fenômenos pode ser suficientemente concebida a partir da forma pura da intuição sensível. Mas todas as leis empíricas são apenas [A 128] determinações particulares das leis puras do entendimento, sob as quais e segundo cuja norma aquelas são primeiramente possíveis e os fenômenos assumem uma forma legal, assim como também todos os fenômenos, a despeito da diversidade da sua forma empírica, ainda assim tem sempre que ser conformes às condições da forma pura da sensibilidade.

O entendimento puro é portanto, nas categorias, a lei da unidade sintética de todos os fenômenos, e através disto torna primeiro e originariamente possível experiência quanto à sua forma. E na dedução transcendental das categorias não tínhamos que realizar mais do que tornar compreensível esta relação do entendimento à sensibilidade e, mediante a mesma, a todos os objetos da experiência, portanto a validade objetiva dos seus conceitos puros a priori, e com isso estabelecer a sua origem e verdade.

\section{Representação sumária da correção e única possibilidade desta dedução dos conceitos puros do entendimento}

Fossem coisas em si mesmas os objetos com os quais está às voltas o nosso conhecimento, deles não poderíamos ter quaisquer conceitos a priori. Pois de onde deveríamos tirá-los? Se os tirássemos do objeto (sem aqui investigarmos mais uma vez como [A 129] este poderia tornar-se conhecido de nós), nossos conceitos seriam meramente empíricos, e não conceitos a priori. Se os tirássemos de nós mesmos, então aquilo que está apenas em nós não pode determinar a constituição de um objeto distinto de nossas representações, ou seja, ser o fundamento pelo qual deva haver uma coisa à qual convenha algo como aquilo que temos em pensamento, e não ser antes vazia toda esta representação. Se ao contrário nós só estamos em toda parte às voltas com fenômenos, então não é só possível, mas também necessário que certos conceitos a priori precedam ao conhecimento empírico dos objetos. Pois como fenômenos eles constituem um objeto que é apenas em nós, já que uma mera modificação de nossa sensibilidade de modo algum pode ser encontrada fora de nós. Ora, a própria representação de que todos estes fenômenos, portanto todos os objetos dos quais nos podemos 
ocupar, estão todos em mim, isto é, são determinações do meu si-mesmo idêntico, expressa como necessária uma unidade pervasiva deles em uma e a mesma apercepção. Nesta unidade da consciência possível, no entanto, também consiste a forma de todo conhecimento dos objetos (pela qual é pensado o múltiplo como pertencente a Um objeto). Portanto, o modo como o múltiplo da representação sensível (intuição) pertence a uma consciência precede a todo conhecimento do objeto como a forma intelectual do mesmo, e [este modo] perfaz, ele mesmo, um conhecimento formal de todos os objetos [A 130] a priori em geral na medida em que são pensados (categorias). A síntese dos mesmos [ $\left[{ }^{17}\right]$ pela imaginação pura, a unidade de todas as representações com referência à apercepção originária precedem a todo conhecimento empírico. Conceitos puros do entendimento só são portanto possíveis a priori, e até mesmo necessários com referência à experiência, pelo fato de o nosso conhecimento não estar às voltas com nada mais senão fenômenos cuja possibilidade está em nós mesmos, cuja conexão e unidade (na representação de um objeto) é encontrada apenas em nós, portanto tem que preceder a toda experiência e torná-la também primeiro possível quanto à forma. E é por esta razão, a única possível dentre todas, que também foi feita a nossa dedução das categorias.

\section{Referencias Bibliográficas}

EMMEL, H.; GEMÜT R. I. Historisches Wörterbuch der Philosophie, hrsg. von RITTER, J. Band 3: G-H. Darmstadt: Wissenschaftliche Buchgesellschaft, 1974, col. 258-262.

KANT, I. Kritik der reinen Vernunft. Nach der ersten und zweiten OriginalAusgabe neu herausgegeben von Raymund Schmidt. Zweite, durchgesehene, um ein Namenregister vermehrte Auflage. Hamburg: Felix Meiner Verlag, 1930.

Werke in zehn Bänden. Hrsg. von Wilhelm Weischedel. Sonderausgabe. Darmstadt: Wissenschaftliche Buchgesellschaft, 1981.

EMAIL: ubm5014@hotmail.com

RECEBIDO: Fevereiro/2013

APROVADO: Maio/2013

17 Texto original ambíguo: "die Synthesis derselben". O "derselben" pode referir-se gramaticalmente a "fenômenos", a "representação sensivel", a "intuição" ou até a "categorias", todos termos femininos em alemão, ou ainda a "objetos", um neutro plural em alemão. 